\title{
Obstructive Sleep Apnoea and Vascular Disease in Patients with Type 2 Diabetes
}

\author{
Abd A Tahrani \\ Centre of Endocrinology, Diabetes and Metabolism, University of Birmingham, Birmingham, UK; Department of Diabetes and \\ Endocrinology, Birmingham Heartlands Hospital, Birmingham, UK
}

\begin{abstract}
Obstructive sleep apnoea (OSA) is common and is associated with many vascular risk factors, such as hypertension, insulin resistance, albuminuria, dyslipidaemia, increased inflammation and endothelial dysfunction. Epidemiological studies have shown that OSA is associated with increased cardiovascular disease (CVD) and that continuous positive airway pressure (CPAP) might reduce CVD events in patients with OSA. In addition, OSA has also been shown to be associated with albuminuria, chronic kidney disease, a wide range of ocular diseases and peripheral neuropathy. Considering that CVD and microvascular complications are major contributors to the morbidity, mortality and the economic burden of diabetes and that OSA is common in patients with type 2 diabetes (T2D), it is important to understand the role of OSA in the development and/or progression of vascular disease in patients with T2D and to explore the impact of CPAP on diabetes-related vascular outcomes. The purpose of this article is to review the evidence for the relationship and impact of OSA on vascular disease and vascular risk factors particularly in patients with T2D.
\end{abstract}

\section{Keywords}

Type 2 diabetes, obstructive sleep apnoea, vascular disease, vascular risk

Disclosure: Abd A Tahrani is a clinician scientist supported by the National Institute for Health Research (NIHR) in the UK. The views expressed in this publication are those of the author and not necessarily those of the National Health Service, the NIHR or the Department of Health. No funding was received for the publication of this article.

Open Access: This article is published under the Creative Commons Attribution Noncommercial License, which permits any non-commercial use, distribution, adaptation and reproduction provided the original author(s) and source are given appropriate credit.

Received: 1 July 2015 Accepted: 10 July 2015 Citation: European Endocrinology, 2015;11(2):81-9 DOI: 10.17925/EE.2015.11.02.81

Correspondence: Abd A Tahrani, Department of Diabetes and Endocrinology, Birmingham Heartlands Hospital, Birmingham B9 5SS, UK. E: Abd.Tahrani@nhs.net

Diabetes-related macro- and microvascular complications contribute significantly to the increased morbidity, mortality, worsened quality of life and social and financial burden observed in patients with diabetes. ${ }^{1-5}$ Hence, reducing the development and/or the progression of these complications is one of the main aims of treatment in patients with diabetes.

Over the last 2 decades, strategies resulting in the improvements of glycaemic control, blood pressure (BP) and lipids and the use of renin angiotensin aldosterone inhibitors, resulted in reductions in cardiovascular disease (CVD) in patients with diabetes, but there was little impact on diabetic microvascular complications. ${ }^{6}$ Nonetheless, both CVD and microvascular complications remain common and a better understanding of the pathogenesis of these complications is needed in order to identify new treatment strategies.

Obstructive sleep apnoea (OSA) is common in patients with type 2 diabetes (T2D) (up to $86 \%$ prevalence), which is not surprising considering that increasing age and obesity are common risk factors to both conditions. ${ }^{7.8}$ OSA is characterised by upper airway instability during sleep that results in recurrent upper airway obstruction resulting in either complete or partial cessation of airflow (i.e. apnoea and hypopnoea, respectively). ${ }^{9}$ The recurrent obstructions of the upper airway usually result in recurrent oxygen desaturations/re-saturations, cyclical changes in intrathoracic pressure (as the patient attempts to breath against a blocked airway) and recurrent micro arousals that cause sleep fragmentation and reduction in slow wave and rapid eye movement (REM) sleep and result in termination of the apnoea/hypopnoea episodes. ${ }^{?}$

Several large epidemiological studies and randomised controlled trials (RCTS) have shown that OSA was associated with CVD and CVD risk factors in general populations, while the impact of OSA on vascular disease in patients with T2D has only gained attention in the last few years. 7,10,11 In this article the evidence of the relationship and impact of OSA on vascular disease and CVD risk factors will be reviewed, particularly in patients with T2D.

\section{Obstructive Sleep Apnoea and Vascular Risk Factors \\ Obstructive Sleep Apnoea and Hypertension}

Several cross-sectional, prospective and interventional studies showed that OSA was associated with sustained hypertension, lack of the nocturnal dipping of BP and incident hypertension and that OSA treatment lowered BP. Most of these studies were not in patients with T2D, but the limited evidence available in patients with T2D seems to support the findings of studies from the general population.

\section{In General Population Studies}

In a cross-sectional analysis from the Sleep Heart Health Study, OSA was associated with hypertension in 6,132 middle-aged and older persons (aged $\geq 40$ years) odds ratio (OR) (95\% confidence interval $[\mathrm{CI}]$ ) for 
hypertension for the highest versus the lowest category of the apnoeahypopnoea index (AHI) was 1.37 (1.03-1.83; p=0.005) after adjustment for body mass index (BMI), neck circumference, waist-hip ratio, alcohol and smoking. ${ }^{12}$ This association was present in men and women, older and younger, multiple ethnic groups and among normal weight and overweight patients..$^{12}$ In the Wisconsin Sleep Cohort Study, OSA was associated with the presence of hypertension in 709 participants after 4 years of follow-up; relative to an AHI of 0 at baseline, the adjusted ORs for the presence of hypertension at follow-up were $1.42(95 \% \mathrm{Cl}$ 1.13-1.78), 2.03 (1.29-3.17) and 2.89 (1.46-5.64) for an AHI of 0.1 to 4.9, 5.0 to 14.9 and $\geq 15.0$ respectively ( $\mathrm{p}=0002$ for the trend). ${ }^{13}$ OSA was also a predictor of incident systolic nocturnal non-dipping of BP (based on 24-hour ambulatory BP) over an average of 7.2 years follow-up in 328 adults from the Wisconsin Sleep Cohort Study (adjusted OR $[95 \% \mathrm{Cl}]$ for baseline AHI 5-14.9 and $\geq 15$, versus AHI $<5$, were 3.1 [1.3-7.7] and 4.4 [1.2-16.3], respectively). ${ }^{14}$

\section{Impact of Obstructive Sleep Apnoea Treatment}

The causality between OSA and hypertension was further confirmed in interventional and RCTs. A recent meta-analysis of RCTs showed that continuous positive airway pressure (CPAP) lowered BP in hypertensive patients with OSA, particularly in relation to diastolic BP, nocturnal systolic BP and in patients receiving anti-hypertensives. ${ }^{15}$ In a RCT of hypertensive patients with OSA in which patients were randomised to oral appliances with or without mandibular advancement, there was a trend for lowering BP in the active versus control groups, particularly in those with $\mathrm{BP}>135 / 85 \mathrm{mmHg}$ and $\mathrm{AHI}>15 .{ }^{16} \mathrm{CPAP}$ also might have had a BP-lowering effect even in those with resistant hypertension. ${ }^{15}$ In a small RCT of moderate to severe OSA patients with resistant hypertension, in which patients were randomised to medical therapy versus CPAP + medical therapy, 6 months of CPAP was associated with greater reductions in systolic and diastolic BP (systolic $+3.1 \pm 3.3$ versus $-6.5 \pm 3.3$; diastolic $+2.1 \pm 2.7$ versus $-4.5 \pm 1.9 \mathrm{~mm} \mathrm{Hg}$; $p<0.05$ for both comparisons). ${ }^{17}$ This effect was mainly for diurnal rather than nocturnal BP. ${ }^{17}$ Another open-label RCT in which patients with moderate to severe OSA and resistant hypertension were randomised to CPAP or no CPAP in addition to usual medical therapy, showed that 12 weeks of CPAP resulted in a greater reduction compared with the control group in terms of the average 24-hour BP $(3.1 \mathrm{~mm} \mathrm{Hg}$ [95 \% Cl 0.6 to 5.6]; $\mathrm{p}=0.02)$ and diastolic $\mathrm{BP}(3.2 \mathrm{~mm} \mathrm{Hg}[95 \% \mathrm{Cl} 1.0$ to 5.4]; $\mathrm{p}=0.005)$, but not systolic BP. ${ }^{18}$ In addition, CPAP resulted in a greater proportion of patients having nocturnal BP dipping compared with the control group (35.9 \% versus $21.6 \%$, adjusted OR 2.4 [95 \% Cl, 1.2 to 5.1]; $\mathrm{p}=0.02$ ). ${ }^{18}$ There was a significant modest positive correlation between hours of CPAP use and the decrease in 24-hour mean BP, diastolic BP and systolic BP (correlation coefficients were $0.25-0.30$ ). ${ }^{18}$ However, not all studies showed similar results; in recent RCTs 3-6 months of CPAP had no impact on BP in patients with moderate to severe OSA and resistant hypertension. ${ }^{19,20}$ Furthermore, in an 8-week RCT with a crossover design, both CPAP and valsartan resulted in a significant reduction in mean 24-hour BP but valsartan was superior to CPAP $(-7.0 \mathrm{~mm} \mathrm{Hg}$, $95 \% \mathrm{Cl}-10.9$ to $-3.1 \mathrm{~mm} \mathrm{Hg}$; $\mathrm{p}<0.001$ ). ${ }^{21}$

The impact of CPAP on incident hypertension was assessed in one RCT, in which 723 patients with $\mathrm{AHI} \geq 20$ and ESS $\leq 10$ were randomised to CPAP versus no CPAP. After 4 years, CPAP treatment had not had any impact on the incidence of hypertension and CVD (combined) in the intention-to-treat analysis (OR $0.83,95 \% \mathrm{Cl} 0.63-1.1 ; \mathrm{p}=0.20$ ), but sub-group analysis showed that adherence to CPAP treatment ( $\geq 4$ hours/night) lowered the incidence of the combined outcome
(OR 0.72, $95 \% \mathrm{Cl}$ 0.52-0.98; $\mathrm{p}=0.04$ ).22 There was no significant impact of CPAP when incident hypertension and incident CVD were analysed separately but this might be related to sample size.

\section{In Patients with Type 2 Diabetes}

Unlike the extensive evidence for the relationship between OSA and hypertension in the general population, data in patients with T2D are rather limited, despite the high prevalence of OSA in patients with T2D and the importance of maintaining good BP targets to reduce diabetesrelated vascular complications. In a large cross-sectional study that included 12,765 patients with hypertension (2,954 with T2D), patients with T2D and either awake BP $\geq 135 / 85 \mathrm{~mm}$ Hg or asleep BP $\geq 120 / 70 \mathrm{~mm} \mathrm{Hg}$, had a higher prevalence of OSA than those with T2D, but lower BP and patients with T2D had a higher prevalence of non-dipping of nocturnal $\mathrm{BP}$ than those without $\mathrm{T} 2 \mathrm{D}_{i}^{23}$ these findings suggest that OSA might contribute to the non-dipping of nocturnal BP in patients with T2D.

\section{Impact of Continuous Positive Airway Pressure}

In a retrospective cohort database study of 221 patients with newly diagnosed OSA, CPAP was associated with a mean change of $-7.44(95 \% \mathrm{Cl}-10.41$ to -4.47$)$ and $-3.14(-4.99$ to -1.29$)$ at 3-6 months and $-6.81 \mathrm{mmHg}(-9.94$ to $-3.67 \mathrm{mmHg})$ and $-3.69 \mathrm{mmHg}(-5.53$ to $-1.85 \mathrm{mmHg}$ ) at $9-12$ months in systolic and diastolic BP, respectively. ${ }^{24}$ Greater adherence was associated with greater reductions in diastolic $\mathrm{BP}$, but the association was modest $\left(\mathrm{R}^{2}=0.04 ; \mathrm{p}=0.04\right) .^{24}$ Another randomised parallel group intervention trial, in which patients with T2D and OSA were randomised to early ( $<1$ week) or late (1-2 months) CPAP for 3 months, showed that CPAP resulted in reductions in systolic and diastolic BP $(149 \pm 23 / 80 \pm 12$ to $140 \pm 18 / 73 \pm 13 \mathrm{~mm} \mathrm{Hg} ; \mathrm{p}=0.005$ and 0.007 for systolic and diastolic BP, respectively) ${ }^{25}$

Clearly, much more evidence is needed before proving causality between OSA and hypertension in patients with T2D. There is a need for randomised placebo and active controlled trials assessing the impact of OSA and CPAP on hypertension in patients with T2D, particularly in those with resistant hypertension.

\section{Obstructive Sleep Apnoea and Insulin Resistance}

Insulin resistance (IR) is an important risk factor for the development of vascular dysfunction and CVD. ${ }^{26-29} \mathrm{IR}$ is also associated with many cardiovascular risk factors such as the metabolic syndrome, hypertension, dyslipidaemia, hypercoagulability and sympathetic activation. ${ }^{28,30-32}$

\section{In General Population Studies}

Several cross-sectional studies showed an association between OSA and IR but some studies did not show such an association.7.10,11 Obesity is obviously a major confounder but the association between OSA and IR was also found in lean individuals, suggesting that the relationship is independent of obesity.33,34 One study examined the effect of OSA on IR longitudinally; over 11-year follow-up OSA, AHI, oxygen desaturation index (ODI) and minimal oxygen saturations overnight were independently associated with IR after adjustment for age, baseline BMI, hypertension, BMI change over follow-up and CPAP treatment. ${ }^{35}$ CPAP was shown to lower IR (improve insulin sensitivity) in several studies and metaanalysis, ${ }^{36-38}$ particularly when CPAP usage was $>4$ hours per night. ${ }^{39}$

\section{In Patients with Type 2 Diabetes}

Data about the impact of OSA on IR in patients with T2D are limited. Two cross-sectional studies from the same group showed that OSA was associated with IR (based on the homeostatic model assessment 
[HOMA]) in patients with T2D. ${ }^{40,41} \mathrm{~A}$ meta-analysis ${ }^{42}$ of two nonrandomised trial ${ }^{43,44}$ showed that CPAP treatment improved insulin sensitivity in patients with T2D suggesting possible causality. Further studies and clinical trials are needed to assess the impact of OSA on IR in patients with T2D, particularly in those with severe IR considering that the pharmacological options to treat severe IR in T2D are limited.

\section{Obstructive Sleep Apnoea and Lipids In General Population Studies}

Many cross-sectional studies examined the relationship between OSA and hyperlipidaemia. The results are conflicting mainly due to differences in the population examined (particularly the choice of the control group, the sample size and the possible confounding effects of CPAP). ${ }^{45,46} \mathrm{~A}$ recent meta-analysis of 64 studies showed that OSA was associated with higher total cholesterol, higher low-density lipoprotein $(\mathrm{LDL})$, higher triglycerides and lower high-density lipoprotein (HDL). ${ }^{45}$ $\mathrm{AHI}$ correlated positively with triglyceride levels and negatively with HDL levels but not with total cholesterol or LDL. ${ }^{45}$ The association between OSA/AHI and triglyceride levels was also evident in non-obese patients ${ }^{34}$ suggesting that relationship is independent of obesity and possibly more related to IR. However, despite these findings, a good evidence of causality between OSA and hyperlipidaemia is lacking, although mechanistically it is plausible that chronic intermittent hypoxia might lead to hyperlipidaemia via the generation of stearoylcoenzyme A desaturase-1 and oxidative stress, peroxidation of lipids and sympathetic activation. ${ }^{46}$

\section{Impact of Continuous Positive Airway Pressure}

The CPAP impact on dyslipidaemia was assessed in several meta-analyses In a meta-analysis that included 29 clinical trials, the majority of which were uncontrolled and not RCTs with a study duration of 3-6 months (range 2 days to 8 months), CPAP reduced total cholesterol and LDL and increased HDL and had no effect on triglycerides. ${ }^{47}$ Another meta-analysis that included only RCTS $(n=6)$ showed slightly different results in that CPAP had no effect on LDL, HDL or triglycerides but CPAP did lower total cholesterol levels particularly in patients who were younger, more obese and who used CPAP for a longer period. ${ }^{48}$ Hence, the impact of CPAP on lipids remains unclear. It needs to be noted that the impact of CPAP might be less relevant than that of lipid-lowering treatments currently available.

\section{In Patients with Type 2 Diabetes}

In patients with $\mathrm{T} 2 \mathrm{D}$, the impact of CPAP is limited to one RCT in which patients were randomised to early versus late CPAP treatment; the combined analysis of both arms showed that 3 months of CPAP had no effect on the lipids. ${ }^{25}$ However, the levels of total cholesterol, LDL, HDL and triglycerides were largely within recommended targets for patients with T2D at baseline and approximately $80 \%$ of the study participants were on lipid-lowering treatment. ${ }^{25}$ Clearly there is need for RCTs and appropriately designed longitudinal studies to understand the impact of OSA on dyslipidaemia in diabetes.

\section{Obstructive Sleep Apnoea, Inflammation and Endothelial Dysfunction}

As OSA is associated with increased oxidative stress and activation of the sympathetic nervous system and free fatty acid release, hence, it is plausible that OSA is associated with increased systematic inflammation. ${ }^{49}$

Chronic intermittent hypoxia, a feature of OSA, was associated with increased nuclear factor $\kappa \mathrm{B}(\mathrm{NF}-\mathrm{\kappa B})$ and hypoxia-inducible factor-1 (HIF-1) in vivo and in vitro; both of which can result in systematic inflammation. ${ }^{50,51}$ OSA has been shown to be associated with increased systematic cytokines such as interleukin (IL)-6, IL-8, tumour necrosis factor alpha (TNF- $\alpha$ ), c-reactive protein (CRP), granulocyte chemotactic protein-2 (GCP-2) and monocyte chemotactic protein-1 (MCP-1) independent of obesity. ${ }^{52-61}$ However, not all studies showed a relationship between OSA and inflammation ${ }^{62,63}$ with obesity being the main confounder. ${ }^{64}$ Whether CPAP reduces systematic inflammation and cytokines is unclear as some studies showed that CPAP reduced systematic inflammation while others did not. $49,65,66$

Adhesion molecules (selectins and integrins) play an important role in inflammation and in the interaction between the endothelium, platelets and white cells..$^{64}$ Polymorphnuclear cells, monocytes and $T$ lymphocytes from patients with OSA had increased adhesion molecules, increased avidity to endothelial cells and increased prolonged lifespan of active polymorphmuclear cells compared with controls. ${ }^{67-74}$ In addition, endothelial cells from patients with OSA showed increased expression of adhesion molecules (intercellular adhesion molecule 1 [ICAM-1], vascular cell adhesion molecules (VCAM) and E-selectin and P-selectin) compared with controls, which might be reversible with CPAP treatment. ${ }^{60,61,75-77}$

Several studies showed that OSA was associated with endothelial dysfunction. OSA patients had reduced circulating and endothelial levels of nitric oxide, which can improve after $\mathrm{CPAP}_{1}^{78-80}$ partly because of reduction in nitric oxide production secondary to the inhibition of nitric oxide synthase. ${ }^{81}$ Patients with OSA exhibited impaired endothelial-dependent and independent vasodilatation ${ }^{82}$ independent of hypertension, ${ }^{83}$ obesity $^{84}$ and cardiovascular risk factors. ${ }^{85}$

In patients with T2D, OSA and hypoxaemia, measures were associated with increased nitrosative stress and oxidative stress despite adjustment for many confounders. ${ }^{64,86} \mathrm{In}$ addition, OSA and lower nadir nocturnal oxygen saturations were also associated with reduction in nitric oxide-induced vasodilation compared with those with T2D but without OSA, despite adjustment for many confounders. ${ }^{86}$

\section{Obstructive Sleep Apnoea and Cardiovascular Disease In General Population Studies}

Several cross-sectional and case-controlled studies showed an association between OSA and CVD. ${ }^{87,88}$ In patients with stable coronary artery disease (CAD), OSA patients had a larger atherosclerotic plaque volume (based on intravascular ultrasound) compared with patients without OSA; the AHI correlated positively with the plaque volume measured by ultrasound $(r=0.6 ; p=0.01)^{89}$ or computed tomography (CT) angiogram $(r=0.4 ; p=0.02) .^{90}$ Patients with OSA were also more likely to develop acute myocardial infarction between 12 am and 6 am compared with matched controls without OSA (32\% versus $7 \% ; p=0.01)^{91}$ supporting the role of nocturnal events in OSA in the development of myocardial infarction.

\section{Longitudinal Studies and the Impact of Continuous Positive Airway Pressure}

Several prospective observational studies have also shown that OSA predicts the development of incident CVD and that CPAP might reduce CVD incidence in patients with OSA. ${ }^{92-97}$ In a study of 182 consecutive middle-aged men who were free of CVD at baseline and were followed up for 7 years, OSA was an independent predictor of incident CVD (adjusted OR 4.9, 95 \% Cl 1.8-13.6). ${ }^{92}$ CPAP treatment was associated 
with a reduction in CVD incidence $(56.8 \%$ versus $6.7 \%$ for incompletely treated versus efficiently treated with CPAP, respectively; $p<0.001) .^{92}$ In another study of men with OSA, patients with untreated severe OSA had a higher incidence of fatal and non-fatal CVD compared with untreated patients with mild to moderate OSA, simple snorers, patients treated with CPAP and healthy participants after a mean follow-up of 10.1 years..$^{93}$ Untreated severe OSA significantly increased the risk of fatal (adjusted OR 2.87, $95 \% \mathrm{Cl}$ 1.17-7.51) and non-fatal (adjusted OR $3.17,95 \% \mathrm{Cl} 1.12-7.51)$ CVD compared with healthy participants..$^{93}$ In another study in which 1,022 patients were followed up for a median of 3.4 years, OSA increased the risk of stroke or death (hazard ratio [HR] 1.97, $95 \% \mathrm{Cl} 1.12-3.48 ; \mathrm{p}=0.01) .{ }^{94}$ In a longitudinal study of 1,189 patients from the general population; $\mathrm{AHI} \geq 20$ was associated with an increased risk of suffering a first-ever stroke over the next 4 years in the unadjusted analysis (OR 4.31, $95 \% \mathrm{Cl} 1.31-14.15 ; \mathrm{p}=0.02$ ), but this association became non-significant after adjustment for age, sex and BMI (OR 3.08, 95 \% Cl 0.74-12.81; $p=0.12) .{ }^{98}$

Not all studies showed that CPAP was associated with a reduction in CVD incidence: in a large cohort of US veterans (over 3 million, $97 \%$ men, average age 60.5 years) and after a median follow-up of 7.7 years, untreated and treated OSA were associated with incident CAD ( $\mathrm{HR} 3.54,95 \% \mathrm{Cl} 3.40$ to 3.6 and $3.06,95 \% \mathrm{Cl} 2.62$ to 3.56 ) and incident stroke (HR 3.48, $95 \%$ Cl 3.28 to 3.64 and HR 3.50, $95 \%$ Cl 2.92 to 4.19) for untreated and treated OSA, respectively. ${ }^{96}$ Finally, a recent study suggested that the impact of OSA on incident CVD might be modulated by age and gender: in a cohort of 1,927 men and 2,495 women who were free of CAD and heart failure at baseline and were followed-up for a median of 8.7 years OSA was an independent predictor of incident CAD only in men younger than 70 years of age (adjusted HR 1.10, $95 \%$ Cl 1.00-1.21 per 10 unit increase in the AHI). ${ }^{97}$ OSA also predicted incident heart failure in men only (adjusted HR 1.13; $95 \%$ Cl 1.02-1.26 per 10 unit increase in $\mathrm{AHI}){ }^{97}$ In another prospective study of 5,422 participants without a history of stroke at baseline, after a median of 8.7 years men in the highest AHI quartile $(>19)$ had an adjusted HR of 2.86 (95 \% Cl 1.1-7.4). In men with AHI 5-25, each one unit increase in AHI was associated with increased stroke risk by $6 \%$ (95 \% Cl 2-10\%): no such associations were found in women. ${ }^{99}$ However, in another prospective study in which the primary outcome was to examine the impact of OSA on a composite endpoint of stroke and CAD in women ( $n=967)$, after a median follow-up of 6.8 years, the untreated OSA group had greater risk of incident stroke and CAD combined compared with the control group (adjusted HR 2.76, $95 \% \mathrm{Cl} 1.35-5.62$ ) and 0.91 (95\% $\mathrm{Cl}$ 0.43-1.95) for the CPAP-treated group. ${ }^{100}$ Most of the impact of untreated OSA was due to increased incident stroke (adjusted HR 6.44; $95 \% \mathrm{Cl} 1.46-28.3$ ) rather than incident CAD (adjusted HR 1.77, $95 \%$ Cl 0.76-4.09). ${ }^{100}$

There is a lack of RCTs assessing the impact of CPAP on CVD incidence in patients with OSA. In one RCT, in which 723 patients with $A H I \geq 20$ and Epworth Sleepiness Scale (ESS) $\leq 10$ were randomised to CPAP versus no CPAP; after 4 years CPAP treatment had no impact on the incidence of hypertension and CVD (combined) in the intention-to-treat analysis (OR 0.83, $95 \% \mathrm{Cl} 0.63-1.1 ; \mathrm{p}=0.20$ ), but subgroup analysis showed that adherence to CPAP treatment ( $\geq 4$ hours/night) lowered the incidence of the combined outcome (OR 0.72, $95 \% \mathrm{Cl} 0.52-0.98 ; \mathrm{p}=0.04$ ). ${ }^{22}$ There was no significant impact of CPAP on incident CVD when analysed separately from hypertension, but this might be related to sample size. Hence, there is a need for RCTs of adequate study duration and sample size to assess the impact of OSA on CVD.

\section{In Patients with Type 2 Diabetes}

The evidence for the relationship between OSA and CVD in T2D is limited. In the Look AHEAD study, AHI was associated with self-reported history of stroke (adjusted OR 2.57, $95 \% \mathrm{Cl}$ 1.03-6.42), but not with CAD in a cross-sectional analysis. ${ }^{101} \mathrm{~A}$ more recent study provided more convincing evidence of an association between OSA and CVD in T2D; in this study 132 consecutive asymptomatic patients with T2D and normal exercise echocardiography for $\leq 8$ years were followed for a median of 4.9 years and found that OSA was associated with incident CAD (adjusted HR 2.2, $95 \% \mathrm{Cl} 1.2-3.9, \mathrm{p}=0.01$ ) and heart failure (adjusted HR 3.5, $95 \%$ Cl 1.4-9.0; $p<0.01$ ). 102 Whether CPAP treatment reduces CVD progression or incidence in patients with $\mathrm{T} 2 \mathrm{D}$ is unknown.

\section{Obstructive Sleep Apnoea and Microvascular Disease}

There are many plausible reasons to postulate that OSA might result in microvascular disease. We have reviewed these potential mechanisms previously in this journal ${ }^{8}$ but, in summary, OSA and intermittent hypoxaemia can result in increased oxidative and nitrosative stress, Poly (ADP-ribose) polymerase (PARP) activation, increased advanced glycation end-products (AGE), protein kinase C (PKC) activation and inflammation in patients with and without diabetes - all of which can result in endothelial dysfunction and microvascular disease. ${ }^{7,11}$

\section{Obstructive Sleep Apnoea and Nephropathy/ Chronic Kidney Disease In General Population Studies}

OSA has been shown to be prevalent in patients with end stage renal disease (30-80\%); ; $103-105$ but the direction of this relationship and causality is not clear. ${ }^{106}$ Several studies examined the association between OSA and albuminuria/renal function; however, the vast majority of these studies were cross-sectional making it difficult to infer causality.

\section{Obstructive Sleep Apnoea and Albuminuria}

In a cross-sectional study of 121 patients with newly diagnosed, untreated hypertension, patients with moderate to severe OSA had higher urinary albumin excretion compared with patients without OSA ( $14.5 \pm 6.9$ versus $10.0 \pm 8.0 \mathrm{mg} / 24$ hours; $\mathrm{p}=0.014$ ) and the AHI was associated with urinary albumin excretion after adjustment for $\mathrm{BP}$ and components of the metabolic syndrome. ${ }^{107}$ Similar results were found in another cross-sectional study of 40 patients with newly diagnosed OSA without diabetes or hypertension that found that the AHI was independently associated with increased urinary albumin creatinine ratio (ACR) after adjustment for gender, age, BMI, hyperlipidaemia, HOMA-IR, blood creatinine, albumin and estimated glomerular filtration rate (eGFR). ${ }^{108}$ In a cross-sectional study of 507 older community-dwelling men (age $76.0 \pm 5.3$ years), patients with severe OSA had greater urinary ACR compared with those without OSA (age- and race-adjusted mean ACR 9.35 versus $6.72 \mathrm{mg} / \mathrm{g}$; $\mathrm{p=0.007)}$ but this difference became non-significant after adjustment for BMI, hypertension and diabetes. ${ }^{109}$ However, \% time of oxygen saturation $<90 \%$ remained significantly associated with urinary ACR after adjustment for age, race, BMl, hypertension and diabetes $(10.35 \mathrm{mg} / \mathrm{g}$ for $\geq 10 \%$ time oxygen saturation $<90$ versus $7.45 \mathrm{mg} / \mathrm{g}$ for $<1 \%$ time oxygen saturation <90; $\mathrm{p}=0.046$ ). ${ }^{109}$ In another study of 496 adults, AHI was an independent predictor of urinary ACR after adjustment for age, ethnicity, BMI, smoking, eGFR, diabetes and hypertension. ${ }^{110}$ In order to address the matter of hypertension as a possible confounder, a cross-sectional study of 62 untreated hypertensive patients with OSA and 70 hypertensive patients without OSA, who were matched for 
age, sex, smoking status, BMl and 24-hour pulse pressure, showed albuminuria to be greater by $57 \%$ in patients with OSA versus those without and urinary ACR correlated with AHI and other markers of OSA severity.111 This relation remained significant following adjustment for confounders. ${ }^{111}$ However, other studies showed no relation between albuminuria or proteinuria and OSA. ${ }^{112-114}$

\section{Obstructive Sleep Apnoea and Renal Function}

Similar to albuminuria, the relationship between OSA and renal function was mainly assessed in cross-sectional studies and the results are conflicting. In a cross-sectional study of selective 91 morbidly obese adults (BMI $48.3 \pm 8.9 \mathrm{~kg} / \mathrm{m}^{2}$ ) before bariatric surgery, serum creatinine was significantly higher in the OSA group $(0.8 \pm 0.2 \mathrm{mg} / \mathrm{dl}$ in no OSA, $0.9 \pm 0.2 \mathrm{mg} / \mathrm{dl}$ in OSA; $\mathrm{p}=0.01)^{112}$ and $\mathrm{AHI}$ remained independently associated with serum creatinine after adjustment. ${ }^{112}$ In a study of 505 men with OSA (defined as respiratory disturbance index $[\mathrm{RDI}] \geq 15$ events/hour), serum cystatin-C correlated with RDI, but this relation was lost after adjustment for possible confounders. ${ }^{115}$ Based on the Mayo clinic formula (and not Modification of Diet in Renal Disease [MDRD]), men with renal impairment had 2.1-fold greater odds of OSA even after adjustments for confounders. ${ }^{115}$ In a similar study by the same group, lower eGFR (based on MDRD) was not associated with higher RDI. ${ }^{116}$ In an interesting cross-sectional study that included 100 patients who already have CKD (eGFR $28.5 \mathrm{ml} /$ minute $/ 1.73 \mathrm{~m}^{2}$ ) and who were not obese $\left(23.1 \mathrm{~kg} / \mathrm{m}^{2}\right)$, a $10 \mathrm{ml} /$ minute $/ 1.73 \mathrm{~m}^{2}$ decrease in eGFR was associated with $42 \%$ increased odds of OSA after adjustment for age, BMI and diabetes mellitus and eGFR was inversely correlated with AHI after adjustment for covariates. ${ }^{117}$

In a prospective study of 858 patients with an average follow-up of 2.1 years, patients with nocturnal hypoxia (defined as oxygen saturation $<90 \%$ for $\geq 12 \%$ of the nocturnal monitoring time) had a significant increase in the adjusted risk of accelerated kidney function loss (defined as decline in eGFR $\geq 4 \mathrm{ml} /$ minute $/ 1.73 \mathrm{~m}^{2}$ per year) compared with controls without hypoxia after adjustment for RDI, age, BMI, diabetes, heart failure and the use of angiotensin-converting-enzyme (ACE) inhibitors or angiotensin receptor blockers (OR 2.89, 95 \% Cl 1.25-6.67). ${ }^{118}$ In this study, OSA was associated with accelerated kidney function loss in the univariate analysis, which became non-significant after adjustment for confounders. ${ }^{118}$ In a large prospective study of a nationally representative cohort of over 3 million $(n=3,079,514)$ US veterans (93\% male) with baseline eGFR $\geq 60 \mathrm{ml} /$ minute $/ 1.73 \mathrm{~m}^{2}$, the risk of incident chronic kidney disease (CKD) (defined as eGFR $<60 \mathrm{ml} / \mathrm{min} / 1.73 \mathrm{~m}^{2}$ ) was greater in untreated (adjusted HR 2.27, $95 \% \mathrm{Cl}$ 2.19-2.36) and treated (adjusted HR 2.79, $95 \% \mathrm{Cl} 2.48$ to 3.13) patients with OSA.96

\section{Impact of Continuous Positive Airway Pressure}

The impact of CPAP on albuminuria is unclear. In an uncontrolled study of 18 patients (four women), the use of CPAP for 1 month resulted in lowering of urinary albumin excretion and urinary ACR by more than $50 \% .{ }^{119}$ In a small pilot, RCT patients with moderate to severe OSA ( $\left.n=13\right)$ were randomised to CPAP for 4 weeks versus no treatment; CPAP resulted in important reductions in urinary albumin compared with no treatment, although this was not statistically significant, most likely due to the small sample size. ${ }^{120}$ Longitudinal and interventional studies assessing the impact of OSA and CPAP on albuminuria are needed.

An uncontrolled clinical trial of 39 patients with newly diagnosed severe OSA on CPAP for 3 months did not result in any changes in serum creatinine or eGFR, but cystatin $C$ (a biomarker of early CKD) declined significantly $(0.87 \pm 0.18$ versus $0.77 \pm 0.21 ; \quad p<0.001) ; 121$ the lack of impact on eGFR may not be surprising considering the short duration of treatment. In another uncontrolled study of 38 patients with OSA, 3 months of CPAP resulted in a decrease in the serum creatinine levels $(0.87 \pm 0.09$ to $0.82 \pm 0.01 \mathrm{mg} / \mathrm{dl} ; \mathrm{p}=0.013)$ and increased eGFR $\left(72.9 \pm 12.0\right.$ to $\left.79.3 \pm 17.9 \mathrm{ml} / \mathrm{minute} / 1.73 \mathrm{~m}^{2} ; \mathrm{p}=0.014\right) .{ }^{122}$

Although the results from these studies are conflicting, the majority showed an association between OSA or one of its parameters and renal function, decline in renal function and/or CKD but the impact of CPAP is unclear and well-designed RCTs are required.

\section{In Patients with Type 2 Diabetes}

Several studies examined the association between OSA and diabetic nephropathy (DN)/CKD, all except one study were cross-sectional. OSA was found to be associated with DN (defined as albuminuria and/or reduced eGFR) in patients with T2D after adjustment for a wide range of potential confounders (adjusted OR 2.64, $95 \% \mathrm{Cl} 1.13-6.16$; $p=0.02$ ). ${ }^{123}$ In this study, patients with OSA had significantly more albuminuria, higher creatinine, lower eGFR and a greater proportion of patients with eGFR $<60 \mathrm{ml} /$ minute/1.73 $\mathrm{m}^{2}$ compared with patients without OSA. ${ }^{23}$ Lower nadir nocturnal oxygen saturation was also associated with DR after adjustment for potential confounders (OR 0.96, $95 \% \mathrm{Cl} 0.93-1.00$; $\mathrm{p}=0.05) .{ }^{23}$ After a 2.5 -year follow-up, the eGFR decline was greater in patients with OSA compared with those without OSA (median $-1.4 \%$ [interquartile range (IQR) -7.7 to 5.2$]$ versus $-5.3 \%$ [ -16.5 to 2.7$]$ versus $-8.7 \%$ [-16.1 to 2.0]; $p=0.003$, for no OSA versus mild versus moderate to severe OSA) and OSA was an independent predictor of study end eGFR ( $B=-4.2 ; p=0.03$ ) and eGFR decline. ${ }^{123}$ Baseline AHI was also an independent predictor of study end eGFR after adjustment $(B=-4.6, p=0.02) .{ }^{123}$ The progression to albuminuria was numerically but not statistically greater in patients with OSA compared those without OSA (22.6 \% versus $13.3 \% ; p=0.23) .{ }^{123}$

In the same observational longitudinal study the use of CPAP was associated with a favourable impact on eGFR decline over the follow-up (median $-1.4 \%$ [IQR $-7.7 \%$ to $5.2 \%$ ] versus $-5.3 \%$ [ $-16.5 \%$ to $2.7 \%$ ] versus $-7.7 \%$ [ $-15.9 \%$ to $-1.8 \%$ ] versus $-10.0 \%$ [-17.2\% to $2.3 \%]$ ) for no OSA versus mild OSA versus moderate to severe OSA CPAP-compliant versus moderate to severe OSA non-compliant with CPAP respectively $\left(p=0.01\right.$ for the trend). ${ }^{123}$

In a study of Japanese patients with $\mathrm{T} 2 \mathrm{D}$, an $\mathrm{ODI} \geq 5$ was independently associated with microalbuminuria in women but not in men after adjustment for confounders. ${ }^{124}$ Another cross-sectional study showed no relationship between OSA and microalbuminuria in patients with T2D, but this study was of a small sample size $(n=52) .{ }^{125}$ In another small study utilising data collected during routine clinical care from 90 patients with T2D and morbid obesity, the time spent with oxygen saturations $<90 \%$ and $\mathrm{AHI}$ correlated with $\mathrm{AHI}$ after adjustment for potential confounders. ${ }^{126}$

It is possible that OSA contributes to the development and/or progression of nephropathy and CKD in patients with $\mathrm{T} 2 \mathrm{D}$, but further well-designed longitudinal studies and interventional trials are needed.

\section{Obstructive Sleep Apnoea and Retinopathy In General Population Studies}

There are no typical retinal changes that are associated with OSA in patients without T2D; however, several cross-sectional studies showed 
that OSA is associated with a variety of ocular lesions. In the Sleep Heart Health Study, 2,927 patients had retinal photographs taken. ${ }^{127}$ The overall prevalence of retinopathy was non-significantly higher in people with higher RDI values; an increase of RDI from 0 to 10 was associated with a predicted decrease in arteriole-to-venule ratio of 0.01. ${ }^{127}$ However, it must be noted that retinal images were obtained from one randomly selected eye after 5 minutes of dark adaptation without the use of dilators. ${ }^{127}$ OSA has been reported to be associated with other eye lesions such as central serous chorioretinopathy, retinal vein thrombosis, ocular hypertension and optic neuropathy. .28-132 $^{-12}$ OSA was also associated with reduced retinal sensitivity, measured with standard automated perimetry compared with age-matched healthy controls. ${ }^{133}$ In another study of 124 patients, the AHI correlated negatively with the nasal retinal nerve fibre layer thickness (measured by optical coherence tomography) after adjustment. ${ }^{134}$

\section{In Patients with Type 2 Diabetes}

Similar to DN, several studies examined the relationship between OSA and DR but they were all cross-sectional, except for one longitudinal study. In Japanese patients undergoing vitreous surgery for advanced diabetic retinopathy (DR), lower oxygen saturations were associated with proliferative DR after adjustment for age, glycated haemoglobin $\left(\mathrm{HbA}_{1 \mathrm{c}}\right)$ and hypertension. ${ }^{135}$ In a study from the UK, OSA was independently associated with DR and maculopathy after adjusting for age, BMI, diabetes duration and hypertension in men with T2D. ${ }^{136}$ Similarly, in another study from the UK, patients with OSA were three to four times more likely to have sight-threatening DR, pre-proliferative/ proliferative DR or maculopathy, after adjustment for a wide range of confounders including gender and ethnicity. ${ }^{137}$

Longitudinally, patients with OSA were more likely to develop preproliferative/proliferative DR (adjusted OR 6.6, $95 \% \mathrm{Cl}$ 1.2-35.1: $\mathrm{P}=0.03)$; patients who were compliant with CPAP treatment had lower progression to pre-proliferative/proliferative DR compared with noncomplaint patients. ${ }^{137}$

Minimum nocturnal oxygen saturations were also associated with DR/maculopathy independent of potential confounders in crosssectional studies. ${ }^{138,139}$ An interesting study of patients receiving antiVEGF treatment for diabetic and age-related macular oedema $(n=103)$ showed patients with poor response to treatment had a significantly higher risk of OSA compared with age-matched controls. ${ }^{140}$ Whether OSA contributed to the lack of efficacy of anti-vascular endothelial growth factor (VEGF) treatment is unclear.

In a proof of concept uncontrolled, hypothesis-generating study, CPAP treatment for 6 months was associated with improvement in visual acuity without an impact on macular oedema/thickness, suggesting improved functionality, rather than actual change in the oedema. ${ }^{141}$

The studies are suggestive of an association between OSA and DR; however, whether this association is with the development or the progression of DR is unclear. It is plausible that OSA is mainly associated with the progression rather than the development of DR; studies from the general population showed that OSA did not result in retinal changes similar to those observed in diabetes. Hence, while the development of DR is primarily dependent on the presence of hyperglycaemia, the progression of DR might be associated with OSA. Further longitudinal studies and interventional trials are needed to assess the impact of OSA on DR.

\section{Obstructive Sleep Apnoea and Neuropathy}

OSA and nocturnal hypoxia have been associated with the development of peripheral neuropathy in three small studies that included a small number of participants $(n<40)$. In a case-control study, patients with severe OSA ( $\mathrm{AHI}>30$ events/hour) had worse parameters (amplitude and velocity) during nerve conduction studies compared with age-matched controls. ${ }^{142}$ In another study, the prevalence of possible polyneuropathy was much higher in OSA patients ( $\mathrm{AHI} \geq 10$ events/hour) than that in age and $\mathrm{BMI}$ matched controls (71 \% versus $33 \%$; $p<0.05$ ). ${ }^{143}$ In addition, the amplitudes of the sensory nerve action potentials were significantly smaller in the OSA group. ${ }^{143}$

One small uncontrolled study of CPAP for 6 months showed that OSA was associated with axonal dysfunction of the peripheral sensory nerves and that CPAP improved the amplitude of action potentials. ${ }^{144}$

A cross-sectional study found that patients with OSA and T2D were more likely to have DN (OR 2.82, $95 \% \mathrm{Cl} 1.44-5.52)$ and foot insensitivity (OR 3.97, $95 \%$ Cl 1.80-8.74) compared with those with T2D but without OSA after adjustment for a large number of potential confounders. ${ }^{86}$

\section{Obstructive Sleep Apnoea and Erectile Dysfunction}

Erectile dysfunction has been recognised as a risk factor for CVD in patients with ${ }^{145}$ and without T2D. ${ }^{146}$ In addition, many CVD risk factors are known to cause erectile dysfunction. ${ }^{147}$ OSA and erectile dysfunction share many risk factors such as older age, obesity and T2D among others and hence it is not surprising that OSA is common in patients with erectile dysfunction and vice versa. ${ }^{147}$ Several population- and clinic-based studies showed that erectile dysfunction was associated with OSA and that erectile dysfunction severity was associated with the severity of OSA and the nocturnal hypoxaemia. ${ }^{147}$ Many of these studies used less than gold standard methods to assess erectile dysfunction including self-reported outcomes. ${ }^{147}$

However, the causality between OSA and erectile dysfunction cannot be proved due to the lack of longitudinal studies and the lack of convincing data from RCTs. ${ }^{147}$

\section{Impact of Continuous Positive Airway Pressure}

In one small RCT ( $n=27), 1$ month of CPAP improved erectile function (assessed by the 5 item international index of erectile function) compared with the control group; ${ }^{148}$ but the control group in this study was no treatment rather than sham CPAP and hence it is difficult to draw conclusions as the study outcome was self-reported and the study was not blinded. ${ }^{147}$ Other uncontrolled and observational studies suggested beneficial effects of CPAP on erectile dysfunction. However, RCTS comparing the effect of CPAP to sildenafil showed that both improved erectile function but sildenafil was superior. ${ }^{147,149-151}$

There are no RCTs that assessed the impact of CPAP on erectile dysfunction in patients with T2D but one uncontrolled study showed that CPAP for 3 months had no effect on sexual function in 35 men with T2D. ${ }^{152}$

\section{Obstructive Sleep Apnoea and Quality of Life}

Several studies found a cross-sectional association between OSA, OSA severity and worse health-related quality of life (QOL). ${ }^{153}$ In the Wisconsin Sleep Cohort Study and the Sleep Heart Health Study, there was a linear association of OSA severity with decrements on the eight Short Form 36 (SF-36) scales. ${ }^{87}$ In another study, patients with OSA had significantly 
lower SF-36 scores compared with controls; nocturnal hypoxaemia and the ESS were independent factors for predicting the total score on the SF-36. ${ }^{154}$ In a recent study, undiagnosed OSA was associated with impairments in QOL independent of sleepiness and OSA-related comorbidities in men aged $<69$ years, but not in those $\geq 70$ years old. ${ }^{155}$

In an uncontrolled clinical trial, OSA was associated with impaired QOL (based on SF-36) and 8 weeks of CPAP improved vitality, social functioning and mental health. ${ }^{156}$ The magnitude of improvement was related to the baseline QOL impairment rather than OSA severity. ${ }^{156}$ Another study found similar results in that 6 months of CPAP improved physical health, levels of independence and psychological health using the World Health Organization QOL questionnaire. ${ }^{157}$ However, a recent study found that the improvement in QOL following starting CPAP was similar in those who were compliant with treatment versus patients who were not treatment compliant. ${ }^{158}$

\section{Summary and Conclusions}

OSA is associated with several vascular risk factors including hypertension, albuminuria, IR, hyperlipidaemia, erectile dysfunction, increased inflammation and endothelial dysfunction. Large epidemiological studies have shown that OSA is associated with increased CVD and that CPAP might reduce CVD events, but evidence from RCTs is generally lacking. OSA has also been associated with chronic kidney disease and neuropathy. OSA is common in patients with T2D and, hence, understanding the impact of OSA on diabetes-related vascular complications is important considering the significant burden of these complications. In patients with T2D, a limited number of studies showed that OSA is associated with several vascular risk factors such as hypertension, IR and endothelial dysfunction. Emerging evidence also suggest that OSA is associated with CVD and diabetes-related microvascular complications including neuropathy, retinopathy and nephropathy in patients with T2D; however, the majority of these studies were cross-sectional and interventional studies are lacking. However, the limited number of prospective studies suggest a link between OSA and the development of CAD, heart failure and CKD and the progression of DR. Hence, clinicians should consider screening for OSA due to this high prevalence of diabetes and potential contribution to vascular disease, but there is a need to conduct larger longitudinal studies and adequately powered well-designed RCTs to further understand the role of OSA in the pathogenesis and treatment of CVD and diabetes-related microvascular complications.
1. Quality of life in type 2 diabetic patients is affected by complications but not by intensive policies to improve blood glucose or blood pressure control (UKPDS 37), U.K. prospective diabetes study group, Diabetes Care, 1999;22:1125-36.

2. de Groot M, Anderson R, Freedland KE, et al., Association of depression and diabetes complications: A meta-analysis, Psychosom Med, 2001;63:619-30.

3. Jacobson AM. Impact of improved glycemic control on quality of life in patients with diabetes, Endocr Pract, 2004;10:502-8.

Al-Maskari F, El-Sadig M, Nagelkerke N, Assessment of the direct medical costs of diabetes mellitus and its complications in the United Arab Emirates, BMC Public Health, 2010;10:679. Wang W, Fu CW, Pan CY, et al., How do type 2 diabetes mellitus-related chronic complications impact direct medical mellitus-related chronic complications impact direct medict
cost in four major cities of urban china? Value Health, cost in four mas:12:923-9.

6. Gregg EW, Li Y, Wang J, et al., Changes in Diabetes-Related Complications in the United States, 1990-2010, N Eng/ J Med, 2014;370:1514-23.

7. Tahrani AA, Ali A, Stevens MJ, Obstructive sleep apnoea and diabetes: an update, Curr Opin Pulm Med, 2013;19:631-8.

8. Tahrani AA, Ali A, Obstructive sleep apnoea and type 2 diabetes, European Endocrinology, 2014;10:43-50.

9. MCNicholas WT, Diagnosis of obstructive sleep apnea in adults, Proc Am Thorac Soc, 2008;5:154-60

10. Altaf QA, Barnett AH, Tahrani AA, Novel therapeutics for type 2 diabetes: insulin resistance, Diabetes Obes Metab, 2015;17:319-34.

11. Tahrani AA, Diabetes and sleep apnea. In: International Textbook of Diabetes Mellitus. Chichester, UK: John Wiley \& Sons Ltd, 2015;316-36.

12. Nieto FJ, Young TB, Lind BK, et al., Association of sleepdisordered breathing, sleep apnea, and hypertension in large community-based study, JAMA, 2000;283:1829-36.

13. Peppard PE, Young T, Palta M, Skatrud J, Prospective study of the association between sleep-disordered breathing and hypertension, N Eng/ J Med, 2000;342:1378-84.

14. Hla KM, Young T, Finn L, et al., Longitudinal association of sleep-disordered breathing and nondipping of nocturnal blood pressure in the Wisconsin Sleep Cohort Study, Sleep, 2008;31:795-800.

15. Hu X, Fan J, Chen S, et al., The role of continuous positive airway pressure in blood pressure control for patients with obstructive sleep apnea and hypertension: A meta-analysis of ranstructive sleep apnea and hypertension. A meta-analysis of

randomized controlled trials, J Clin Hypertens, 2015; 17:215-22, 6. Andrén $\mathrm{A}$, Hedberg $\mathrm{P}$, Walker-Engström ML, et al., Effects
of treatment with oral appliance on $24-\mathrm{h}$ blood pressure in patients with obstructive sleep apnea and hypertension: a randomized clinical trial, Sleep Breath, 2013;17:705-12.

7. Pedrosa RP, Drager LF, de Paula LKG, et al., Effects of osa treatment on bp in patients with resistant hypertension: $\mathrm{A}$ randomized trial, Chest, 2013;144:1487-94.

18. Martínez-García M, Capote F, Campos-Rodríguez F, Effect of cpap on blood pressure in patients with obstructive sleep apnea and resistant hypertension: The hiparco randomized clinical trial, JAMA, 2013;310:2407-15.

19. Muxfeldt ES, Margallo V, Costa LMS, et al., Effects of continuous positive airway pressure treatment on clinic and ambulatory blood pressures in patients with obstructive sleep apnea and resistant hypertension: A randomized controlled trial, Hypertension, 2015;65:736-42.

20. Lloberes P, Sampol G, Espinel E, et al., A randomized controlled study of CPAP effect on plasma aldosterone concentration in patients with resistant hypertension and obstructive sleep apnea, J Hypertens, 2014;32:1650-7

21. Pépin JL, Tamisier R, Barone-Rochette G, et al., Comparison of continuous positive airway pressure and valsartan in hypertensive patients with sleep apnea, Am J Respir Crit Care Med, 2010;182:954-60

22. Barbé F, Durán-Cantolla J, Sánchez-de-la-Torre M, Effect of continuous positive airway pressure on the incidence of hypertension and cardiovascular events in nonsleepy patients with obstructive sleep apnea: A randomized controlled trial, JAMA, 2012;307:2161-8.

23. Ayala $D E$, Moyá A, Crespo JJ, et al., Circadian pattern of ambulatory blood pressure in hypertensive patients with and without type 2 diabetes, Chronobiol Int, 2012;30:99-115.

24. Prasad B, Carley DW, Krishnan JA, et al., Effects of positive airway pressure treatment on clinical measures of hypertension and type 2 diabetes, J Clin Sleep Med, 2012;8:481-7.

25. Myhill PC, Davis WA, Peters KE, et al., Effect of continuous positive airway pressure therapy on cardiovascular risk factors in patients with type 2 diabetes and obstructive sleep apnea, J Clin Endocrinol Metab, 2012;97:4212-8.

26. Stumvoll M, Goldstein BJ, van Haeften TW, Type 2 diabetes: principles of pathogenesis and therapy, Lancet, 2005;365:1333-46

27. Howard G, O'Leary DH, Zaccaro D, et al., Insulin sensitivity and atherosclerosis, Circulation, 1996;93:1809-17.

28. DeFronzo RA, Ferrannini $E$, Insulin resistance: a multifaceted syndrome responsible for NIDDM, obesity, hypertension, syndrome responsible for NIDDM, obesity, hypertension,
dyslipidemia, and atherosclerotic cardiovascular disease, dyslipidemia, and atherosclerotic
Diabetes Care, 1991;14:173-94.

29. Roberts $\mathrm{AC}$, Porter KE, Cellular and molecular mechanisms of endothelial dysfunction in diabetes, Diabetes and Vascula Disease Research, 2013;10(6):472-482.

30. Muniyappa R, Sowers JR, Role of insulin resistance in endothelial dysfunction, Reviews in Endocrine and Metabolic Disorders, 2013;14(1):5-12.

31. Ginsberg HN, Insulin resistance and cardiovascular disease, Rev Endocr Metab Disord, 2000;106:453-8.

32. Lambert GW, Straznicky NE, Lambert EA, et al., Sympathetic nervous activation in obesity and the metabolic syndromecauses, consequences and therapeutic implications, causes, consequences and therap
Pharmacol Ther, 2010;126:159-72.

33. Pamidi S, Wroblewski K, Broussard J, et al., Obstructive sleep apnea in young lean men: Impact on insulin sensitivity and apnea in young lean men: Impact on insul

34. Lin QC, Zhang XB, Chen GP, et al., Obstructive sleep apnea syndrome is associated with some components of metabolic syndrome in nonobese adults, Sleep Breath, 2012;16:571-8.

35. Lindberg E, Theorell-Haglöw J, Svensson M, et al., Sleep apnea and glucose metabolism: A long-term follow-up in a community-based sample, Chest, 2012;142:935-42.

36. Yang D, Liu Z, Yang H, Luo Q, Effects of continuous positive airway pressure on glycemic control and insulin resistance in patients with obstructive sleep apnea: a meta-analysis, Sleep Breath, 2013;17:33-8.

37. Iftikhar IH, Khan MF, Das A, Magalang UJ, Meta-analysis: Continuous positive airway pressure improves insulin resistance in patients with sleep apnea without diabetes, Annals ATS, 2013;10:115-20.

38. Iftikhar IH, Hoyos CM, Phillips CL, Magalang UJ, Meta-analyses of the association of sleep apnea with insulin resistance, an the effects of CPAP on HOMA-IR, Adiponectin, and Viscera adipose fat, J Clin Sleep Med, 2015;11:475-85.
39. Yang D, Liu Z, Yang H, The impact of effective continuous positive airway pressure on homeostasis model assessment insulin resistance in non-diabetic patients with moderate to severe obstructive sleep apnea, Diabetes Metab Res Rev, 2012;28:499-504.

40. Hermans MP, Ahn SA, Rousseau MF, Cardiometabolic phenotype and UKPDS risk in male type 2 diabetic patients with obstructive sleep apnoea, Diabetes Metab Res Rev, 2009;3:50-4.

41. Hermans MP, Ahn SA, Mahadeb YP, Rousseau MF, Sleep apnoea syndrome and 10-year cardiovascular risk in females with type 2 diabetes: relationship with insulin secretion and insulin
resistance, Diabetes Metab Res Rev, 2013;29:227-34.

42. Chen L, Pei JH, Chen HM, Effects of continuous positive airway pressure treatment on glycaemic control and insulin sensitivity in patients with obstructive sleep apnoea and type 2 diabetes: a meta-analysis, Arch Med Sci, 2014;10:637-42.

43. Harsch IA, Schahin SP, Brückner K, et al., The effect of continuous positive airway pressure treatment on insulin sensitivity in patients with obstructive sleep apnoea syndrome and type 2 diabetes, Respiration, 2004;71:252-9.

44. Brooks BELI, Cistulli PA, Borkman M, et al., Obstructive sleep apnea in obese noninsulin-dependent diabetic patients: effect of continuous positive airway pressure treatment on insulin responsiveness, JCEM, 1994;79:1681-5.

45. Nadeem R, Singh M, Nida M, et al., Effect of obstructive sleep apnea hypopnea syndrome on lipid profile: A meta-regression analysis, J Clin Sleep Med, 2014;10:475-89.

46. Adedayo A, Olafiranye O, Smith D, et al., Obstructive sleep apnea and dyslipidemia: evidence and underlying mechanism, Sleep Breath, 2014;18:13-8.

47. Nadeem R, Singh $M$, Nida M, et al., Effect of cpap treatment for obstructive sleep apnea hypopnea syndrome on lipid profile: A Meta-Regression Analysis, J Clin Sleep Med, 2014;10:1295-302

48. $\mathrm{Xu} \mathrm{H}$, Yi H, Guan J, Yin S, Effect of continuous positive airway pressure on lipid profile in patients with obstructive sleep apnea syndrome: A meta-analysis of randomized controlled trials, Atherosclerosis, 2014;234:446-53.

49. Jullian-Desayes I, Joyeux-Faure M, Tamisier R, et al., Impact of obstructive sleep apnea treatment by continuous positive airway pressure on cardiometabolic biomarkers: A systematic review from sham CPAP randomized controlled trials, Sleep Medicine Reviews, 2015;21:23-38.

50. Greenberg $\mathrm{H}$, Ye X, Wilson D, et al., Chronic intermittent hypoxia activates nuclear factor-KB in cardiovascular tissues in vivo, Biochem Biophys Res Commun, 2006;343:591-6.

51. Toffoli S, Feron O, Raes M, Michiels $C$, Intermittent hypoxia changes HIF-1 $\alpha$ phosphorylation pattern in endothelial cells: Unravelling of a new PKA-dependent regulation of $\mathrm{HIF-1 \alpha}$ Biochimica et Biophysica Acta, 2007;1773:1558-71.

52. Alberti A, Sarchielli P, Gallinella E, et al., Plasma cytokine levels in patients with obstructive sleep apnea syndrome: a preliminary study, I Sleep Res, 2003;12:305-11.

53. Liu H, Liu J, Xiong S, et al., The change of interleukin-6 and tumor necrosis factor in patients with obstructive sleep apnea syndrome, J Tongji Med Univ, 2000;20(3):200-2.

54. Vgontzas AN, Papanicolaou DA, Bixler EO, et al., Sleep apnea and daytime sleepiness and fatigue: Relation to visceral obesity, insulin resistance, and hypercytokinemia, I Clin obesity, insulin resistance, and hype
Endocrinol Metab, 2000;85:1151-8.

55. Ciftci TU, Kokturk O, Bukan N, Bilgihan A, The relationship between serum cytokine levels with obesity and obstructive sleep apnea syndrome, Cytokine, 2004;28:87-91. 
56. Bravo ML, Serpero L, Barcelo A, et al., Inflammatory proteins in patients with obstructive sleep apnea with and withou daytime sleepiness, Sleep Breath, 2007;11(3):177-85.
Minoguchi K, Yokoe T, Tazaki T, et al., Increased carotid 57. Minoguchi K, Yokoe T, Tazaki T, et al., Increased carotid intima-media thickness and serum inflammatory markers
in obstructive sleep apnea, Am J Respir Crit Care Med, 2005;172:625-30.

58. Hayashi M, Fujimoto K, Urushibata K, et al., Hypoxiasensitive molecules may modulate the development of atherosclerosis in sleep apnoea syndrome, Respirology, 2006:11:24-31.

59. Arnardottir ES, Mackiewicz M, Gislason T, et al., Molecular signatures of obstructive sleep apnea in adults: a review and perspective, Sleep, 2009:32:447-70

60. Ursavas A, Karadag M, Rodoplu E, et al., Circulating ICAM-1 and VCAM-1 levels in patients with obstructive sleep apnea syndrome, Respiration, 2007;74:525-32.

61. Ohga $E$, Tomita T, Wada $H$, et al., Effects of obstructive sleep apnea on circulating ICAM-1, IL-8, and MCP-1, J Appl Physiol, 2003;94:179-84

62. Sharma SK, Mishra HK, Sharma H, et al., Obesity, and not obstructive sleep apnea, is responsible for increased serum hs-CRP levels in patients with sleep-disordered breathing in Delhi, Sleep Medicine, 2008;9:149-56.

63. Imagawa S, Yamaguchi Y, Ogawa K, et al., Interleukin-6 and tumor necrosis factor-alpha in patients with obstructive sleep apnea-hypopnea syndrome. Respiration, 2004;71:24-9.

64. Tahrani A, Ali A, Oxidative stress, inflammation and endothelial dysfunction: The link between obstructive sleep apnoea and vascular disease in type 2 diabetes. In: Obrosova I, Stevens MJ, Yorek MA, editors, Studies in Diabetes, Springer New York, 2014:149-71.

65. Nadeem R, Molnar J, Madbouly EM, et al., Serum inflammatory markers in obstructive sleep apnea: a metaanalysis, J Clin Sleep Med, 2013;9:1003-12.

66. Stradling JR, Craig SE, Kohler M, et al., Markers of inflammation: data from the MOSAIC randomised trial of CPAP for minimally symptomatic OSA, Thorax, 2015;70:181-2

67. Dyugovskaya L, Lavie P, Lavie L, Lymphocyte activation as a possible measure of atherosclerotic risk in patients

68. Dyugovskaya L, Lavie P, Hirsh M, Lavie L, Activated CD8+ T-lymphocytes in obstructive sleep apnoea, Eur Respir J, 2005:25:820-8.

69. Dyugovskaya L, Polyakov A, Lavie P, Lavie L, Delayed neutrophil apoptosis in patients with sleep apnea, $A m$ 」 Respir Crit Care Med, 2008:177:544-54.

70. Dyugovskaya L, Lavie P, Lavie L, Increased adhesion molecules expression and production of reactive oxygen species in leukocytes of sleep apnea patients, Am J Respir Crit Care Med, 2002;165:934-9.

1. Lavie L, Dyugovskaya L, Polyakov A, Biology of periphera blood cells in obstructive sleep apnea-the tip of the iceberg, Arch Physiol Biochem 2008;114:244-54.

72. Lavie L, Oxidative stress inflammation and endothelial dysfunction in obstructive sleep apnea, Front Biosci (Elite Ed) 2012;4:1391-403.

73. Schulz R, Mahmoudi S, Hattar K, et al., Enhanced release of superoxide from polymorphonuclear neutrophils in obstructive sleep apnea. Impact of continuous positive airway pressure therapy, Am I Respir Crit Care Med, 2000;162(2 Pt 1):566-70.

74. Dyugovskaya L, Polyakov A, Cohen-Kaplan V, et al., Bax/Mcl-1 balance affects neutrophil survival in intermittent hypoxia and obstructive sleep apnea: effects of P38MAPK and ERK1/2 signaling, J Trans/ Med, 2012;10:211.

75. Zamarron-Sanz C, Ricoy-Galbaldon J, Gude-Sampedro F, Riveiro-Riveiro A, Plasma levels of vascular endothelial markers in obstructive sleep apnea, Arch Med Res, 2006;37:552-5.

76. Chin K, Nakamura T, Shimizu K, et al., Effects of nasal continuous positive airway pressure on soluble cell adhesion molecules in patients with obstructive sleep apnea syndrome, Am J Med, 2000; 109:562-7.

77. Minoguchi K, Yokoe T, Tazaki T, et al., Silent brain infarction and platelet activation in obstructive sleep apnea, Am J Respir Crit Care Med, 2007:175:612-7.

78. Schulz R, Schmidt D, Blum A, et al., Decreased plasma levels of nitric oxide derivatives in obstructive sleep apnoea: response to CPAP therapy, Thorax, 2000;55:1046-51.

9. Ip MS, Lam B, Chan LY, et al., Circulating nitric oxide is suppressed in obstructive sleep apnea and is reversed by nasal continuous positive airway pressure, Am J Respir Crit Care Med, 2000;162:2166-71

80. Jelic S, Padeletti M, Kawut SM, et al., Inflammation, Oxidative stress, and repair capacity of the vascular endothelium in obstructive sleep apnea, Circulation, 2008:117:2270-8.

81. Ohike Y, Kozaki K, lijima K, et al., Amelioration of vascular endothelial dysfunction in obstructive sleep apnea syndrome by nasal continuous positive airway pressure-possible involvement of nitric oxide and asymmetric NG, NGinvolvement of nitric oxide and asymme.

82. Yim-Yeh S, Rahangdale S, Nguyen ATD, et al., Vascular dysfunction in obstructive sleep apnea and type 2 diabetes mellitus, Obesity, 2011:19:17-22

83. Carlson JT, Rångemark $\mathrm{C}$, Hedner JA, Attenuated endotheliumdependent vascular relaxation in patients with sleep apnoea, $J$ Hypertens, 1996;14:577-84

84. Kato M, Roberts-Thomson P, Phillips BG, et al., Impairment of endothelium-dependent vasodilation of resistance vessels in patients with obstructive sleep apnea, Circulation, 2000;102:2607-10
85. Nieto FJ, Herrington DM, Redline $S$, et al., Sleep apnea and markers of vascular endothelial function in a large community sample of older adults, Am J Respir Crit Care Med, 2004;169:354-60

86. Tahrani AA, Ali A, Raymond NT, et al., Obstructive sleep apnea and diabetic neuropathy: a novel association in patients with type 2 diabetes, Am J Respir Crit Care Med, 2012;186:434-41.

87. Young T, Peppard PE, Gottlieb DJ, Epidemiology of obstructive sleep apnea: A population health perspective, Am J Respir Crit Care Med, 2002;165:1217-39.

88. Martinez D, Klein C, Rahmeier L, et al., Sleep apnea is a stronger predictor for coronary heart disease than traditional

89. Turmel 」 Sériès $\mathrm{F}$ Boulet LP, et al., Relationship between atherosclerosis and the sleep apnea syndrome: An intravascular ultrasound study, Int I Cardiol, 2009;132:203-9.

0. Kent BD, Garvey JF, Ryan S, et al., Severity of obstructive sleep apnoea predicts coronary artery plaque burden: a coronary CT angiography study, Eur Respir J, 2013;42:1263-70.

91. Sert Kuniyoshi FH, Garcia-Touchard A, Gami AS, et al., Daysleep apnea, J Am Coll Cardiol, 2008;52:343-6.

92. Peker Y, Hedner J, Norum J, et al., Increased incidence of cardiovascular disease in middle-aged men with obstructive sleep apnea: A 7-year follow-up, Am J Respir Crit Care Med, 2002;166:159-65.

93. Marin JM, Carrizo SJ, Vicente E, Agusti AG, Long-term cardiovascular outcomes in men with obstructive sleep apnoea-hypopnoea with or without treatment with continuous positive airway pressure: An observational study Lancet, 2005;365:1046-53.

94. Yaggi HK, Concato J, Kernan WN, et al., Obstructive sleep apnea as a risk factor for stroke and death, New Eng/ I Med 2005;353:2034-41.

95. Ou Q, Chen YC, Zhuo SQ, et al., Continuous positive airway pressure treatment reduces mortality in elderly patients with moderate to severe obstructive severe sleep apnea: A cohort study, PLOS ONE, 2015;10:e0127775.

96. Molnar MZ, Mucsi I, Novak M, et al., Association of incident obstructive sleep apnoea with outcomes in a large cohort of US veterans, Thorax, 2015 [Epub ahead of print].

97. Gottlieb DJ, Yenokyan G, Newman AB, et al., Prospective study of obstructive sleep apnea and incident coronary heart disease and heart failure: The sleep heart health study, Circulation, 2010;122:352-60.

98. Arzt M, Young T, Finn L, et al., Association of sleep-disordered breathing and the occurrence of stroke, Am J Respir Crit Care Med, 2005;172:1447-51.

99. Redline S, Yenokyan G, Gottlieb DJ, et al., Obstructive sleep apnea-hypopnea and incident stroke, Am J Respir Crit Care Med, 2010;182:269-77.

100. Campos-Rodriguez F,Martinez-Garcia MA, Reyes-Nuñez N, et al., Role of sleep apnea and continuous positive airway pressure therapy in the incidence of stroke or coronary heart disease in women, Am J Respir Crit Care Med, 2014;189:1544-50

101. Rice TB, Foster GD, Sanders MH, et al., The relationship between obstructive sleep apnea and self-reported stroke or coronary heart disease in overweight and obese adults with type 2 diabetes mellitus, Sleep, 2012;35:1293-8.

102. Seicean S, Strohl KP, Seicean A et al., Sleep disordered breathing as a risk of cardiac events in subjects with diabetes mellitus and normal exercise echocardiographic findings, Am J Cardiol, 2013;111:1214-20.

103. Kimmel PL, Miller G, Mendelson WB, Sleep apnea syndrome in chronic renal disease, Am J Med, 1989;86:308-14.

104. Unruh ML, Sanders MH, Redline S, et al., Sleep apnea in patients on conventional thrice-weekly hemodialysis: comparison with matched controls from the sleep heart health study, J Am Soc Nephrol, 2006;17:3503-9.

105. Wadhwa NK, Seliger M, Greenberg HE, et al., sleep related respiratory disorders in end-stage renal disease patients on peritoneal dialysis, Perit Dial Int, 1992;12:51-6.

106. Hanly PJ, Ahmed SB, Sleep apnea and the kidney: Is sleep apnea a risk factor for chronic kidney disease? Chest 2014;146:1114-22.

107. Prejbisz A, Florczak E, Pregowska-Chwala B, et al , Relationship between obstructive sleep apnea and markers of cardiovascular alterations in never-treated hypertensive patients, Hypertens Res, 2014;37:573-9.

108. Chou YT, Lee PH, Yang CT, et al., Obstructive sleep apnea: a stand-alone risk factor for chronic kidney disease Nephrology Dialysis Transplantation, 2011;26:2244-50.

109. Canales M, Paudel M, Taylor B, et al., Sleep-disordered breathing and urinary albumin excretion in older men, Sleep Breath, 2011;15:137-44.

110. Faulx MD, Storfer-Isser A, Kirchner HL, et al., Obstructive sleep apnea is associated with increased urinary albumin excretion, Sleep, 2007;30:923-9.

111. Tsioufis C, Thomopoulos C, Dimitriadis K, et al., Association of obstructive sleep apnea with urinary albumin excretion in essential hypertension: a cross-sectional study, Am I Kidney Dis, 2008:52:285-93.

112. Agrawal V, Vanhecke TE, Rai B, et al., Albuminuria and renal function in obese adults evaluated for obstructive sleep apnea, Nephron Clin Pract, 2009;113:c140-c147.

113. Casserly LF, Chow N, Ali S, et al., Proteinuria in obstructive sleep apnea, Kidney Int, 2001;60:1484-9.

114. Mello P, Franger M, Boujaoude Z, et al., Night and day proteinuria in patients with sleep apnea, Am J Kidney Dis, 2004;44:636-41.

115. Canales MT, Taylor BC, Ishani A, et al., Reduced renal function and sleep-disordered breathing in community-dwelling elderly men, Sleep Med, 2008;9:637-45.

116. Canales MT, Lui LY, Taylor BC, et al., Renal function and sleepdisordered breathing in older men, Nephrol Dial Transplant, 2008;23:3908-14.

117. Sakaguchi Y, Shoji T, Kawabata H, et al., High prevalence of obstructive sleep apnea and its association with renal function among nondialysis chronic kidney disease patients in japan: A cross-sectional study, Clin J Am Soc Nephrol, 2011;6:995-1000.

118. Ahmed SB, Ronksley PE, Hemmelgarn BR, et al., Nocturnal hypoxia and loss of kidney function, PLOS ONE 2011:6:e19029.

119. Yasar ZA, Ucar ZZ, Demir AU, et al., Does CPAP therapy alter urinary albumin level in adult patients with moderate to severe obstructive sleep apnea syndrome? Sleep Breath 2014;18:525-32

120. Comondore V, Cheema R, Fox J, et al., The impact of CPAP on cardiovascular biomarkers in minimally symptomatic patients with obstructive sleep apnea: A pilot feasibility randomized crossover trial, Lung, 2009;187:17-22.

121. Zhang XB, Jiang $X T$, Lin QC, et al., Effect of continuous positive airway pressure on serum cystatin C among obstructivesleep apnea syndrome patients, Int Urol Nephrol, 2014;46:1997-2002.

122. Koga S, Ikeda S, Yasunaga T, et al., Effects of nasal continuous positive airway pressure on the glomerular filtration rate in patients with obstructive sleep apnea syndrome, Int Med 2013:52:345-9.

123. Tahrani AA, Ali A, Raymond NT, et al., Obstructive sleep apnea and diabetic nephropathy: A cohort study. Diabetes Care 2013;36:3718-25.

124. Furukawa S, Saito I, Yamamoto S, et al., Nocturnal intermitten hypoxia as an associated risk factor for microalbuminuria in Japanese patients with type 2 diabetes mellitus, Eur J Endocrinol, 2013;169:239-46.

125. Buyukaydin B, Akkoyunlu ME, Kazancioglu R, et al., The effect of sleep apnea syndrome on the development of diabetic nephropathy in patients with type 2 diabetes, Eur J Endocrinol, 2012;98:140-3.

126. Leong WB, Nolen M, Thomas GN, et al., The impact of hypoxemia on nephropathy in extremely obese patients with type 2 diabetes mellitus, I Clin Sleep Med, 2014;10:773-8.

127. Boland LL, Shahar E, Wong TY, et al., Sleep-disordered breathing is not associated with the presence of retinal microvascular abnormalities: The sleep heart health study, Sleep, 2004;27:467-73.

128. Kloos $P$, Laube I, Thoelen $A$, Obstructive sleep apnea in patients with central serous chorioretinopathy, Graefes Arch Clin Exp Ophthalmol, 2008;246:1225-8.

129. Leveque TK, Yu L, Musch DC, et al., Central serous chorioretinopathy and risk for obstructive sleep apnea, Sleep Breath, 2007;11:253-7.

130. Karakucuk S, Goktas S, Aksu M, et al., Ocular blood flow in patients with obstructive sleep apnea syndrome (OSAS), Graefes Arch Clin Exp Ophthalmol, 2008;246:129-34.

131. Leroux Les JG, Glacet-Bernard A, Lasry S, et al., [Retinal vein occlusion and obstructive sleep apnea syndrome.], J Fr Ophtalmol, 2009;32:420-4.

132. Brodie FL, Charlson ES, Aleman TS, et al., Obstructive sleep apnea and central serous chorioretinopathy, Retina, 2015;35:238-43.

133. Ferrandez B, Ferreras A, Calvo P, et al., Retinal sensitivity is reduced in patients with obstructive sleep apneaobstructive sleep apnea and visual field, Invest Ophthalmol Vis SCI, 2014;55:7119-25.

34. Shiba T, Takahashi M, Sato Y, et al., Relationship between severity of obstructive sleep apnea syndrome and retina nerve fiber layer thickness, Am J Ophthalmol, 2014;157:1202-8.

135. Shiba T, Maeno T, Saishin Y, et al., nocturnal intermittent serious hypoxia and reoxygenation in proliferative diabetic retinopathy cases, Am J Ophthalmol, 2010;149:959-63.

136. West SD, Groves DC, Lipinski HJ, et al., The prevalence of retinopathy in men with Type 2 diabetes and obstructive retinopathy in men with Type 2 diabetes and

137. Tahrani AA, Dodson P, Ali A, et al., Obstructive sleep apnoea is associated with sight threatening retinopathy and predicts the development of preproliferative and proliferative retinopathy in patients with type 2 diabetes: a longitudinal analysis, Eur J Ophthalmol, 2013;23:449.

138. Nishimura A, Kasai T, Tamura H, et al., Relationship between sleep disordered breathing and diabetic retinopathy: Analysis of 136 patients with diabetes, Diabetes Res Clin Pract, 2015 [Epub ahead of print].

139. Banerjee D, Leong WB, Arora T, et al., The potential association between obstructive sleep apnea and diabetic retinopathy in severe obesity-The role of hypoxemia, PLOS ONE, 2013;8(11):e79521.

140. Nesmith BL, Ihnen M, Schaal S, Poor responders to bevacizumab pharmacotherapy in age-related macular degeneration and in diabetic macular edema demonstrate 
143. Ludemann P, Dziewas $R$, Soros $P$ et al Axonal polyneuropathy in obstructive sleep apnoea, JNeurol Neurosurg Psychiatry, 2001,70.685-7.

144. Dziewas R, Schilling M, Engel P, et al., Treatment fo obstructive sleep apnoea: Effect on peripheral nerve function, I Neurol Neurosurg Psychiatry, 2007;78:295-7.

145. Ma RC-W, So WY, Yang X, et al., Erectile dysfunction predicts coronary heart disease in type 2 diabetes, J Am Coll Cardio 2008;51:2045-50.

146. Inman BA, Sauver JLS, Jacobson DJ, et al., A population-based, Iongitudinal study of erectile dysfunction and future coronary artery disease, Mayo Clinic Proceedings, 2009;84:108-13.

147. Hoyos CM, Melehan KL, Phillips CL, et al., To ED or not to ED-Is erectile dysfunction in obstructive sleep apnea to ED-IS erectile dysfunction in obstructive sleep apnea
related to endothelial dysfunction? Sleep Medicine Reviews, related to encis:20:5-14.

148. Li F, Feng Q, Zhang X, Liu Q, [Treatment for erectile dysfunction patients with obstructive sleep apnea syndrome by nasal continual positive airway pressure], Zhonghua nan ke xue=National Journal of Andrology, 2004;10:355-7.
149. Perimenis P, Karkoulias K Markou S, et al. Erectile dysfunction in men with obstructive sleep apnea syndrome: a andomized study of the efficacy of sildenafil and continuous positive airway pressure, Int J Impot Res, 2004;16:256-60.

150. Perimenis P, Karkoulias K, Konstantinopoulos A, et al., Sildenafil versus continuous positive airway pressure for erectile dysfunction in men with obstructive sleep apnea: a comparative study of their efficacy and safety and the patient's satisfaction with treatment, Asian J Androl, 2007:9:259-64.

151. Li X, Dong Z, Wan Y, Wang Z, Sildenafil versus continuous positive airway pressure for erectile dysfunction in men with obstructive sleep apnea: a meta-analysis, Aging Male 2010;13:82-6.

152. Knapp A, Myhill PC, Davis WA, et al., Effect of continuous positive airway pressure therapy on sexual function and serum testosterone in males with type 2 diabetes and obstructive sleep apnoea, Clin Endocrinol, 2014;81:254-8.

153. Lacasse Y, Godbout C, Sèriés F. Health-related quality of life in obstructive sleep apnoea, Eur Respir J, 2002;19:499-503.
154. Akashiba T, Kawahara S, Akahoshi T, et al., Relationship between quality of life and mood or depression in patients with severe obstructive sleep apnea syndrome*, Chest, 2002;122:861-5.

155. Appleton S, Vakulin A, McEvoy RD, et al., Undiagnosed obstructive sleep apnea is independently associated with reductions in quality of life in middle-aged, but not elderly men of a population cohort, Sleep Breath, 2015;1-8.

156. D'Ambrosio C, Bowman T, Mohsenin V, Quality of life in patients with obstructive sleep apnea*: Effect of nasal continuous positive airway pressure-a prospective study Chest, 1999;115:123-9.

157. Diamanti C, Manali E, Ginieri-Coccossis M, et al., Depression, physical activity, energy consumption, and quality of life in OSA patients before and after CPAP treatment, Sleep Breath, OSA patients befo

158. Bjornsdottir E, Keenan BT, Eysteinsdottir B, et al., Quality of life among untreated sleep apnea patients compared with the general population and changes after treatment with positive airway pressure, I Sleep Res, 2015;24:328-38. 